\title{
Clinical Profile and Visual Outcome of Optic Neuritis Patients in Mysore Medical College and Research Institute, India
}

\author{
Gajaraj Tulsidas Naik ${ }^{1}$, Hemalatha Krishnamurthy², Pradeep Kumar S.M. ${ }^{3}$, Suria Rashmi' \\ Meghana Neeralgi ${ }^{5}$, Asma M.K. ${ }^{6}$, Varna Shet ${ }^{7}$, Sheetal Vaijanath Zille ${ }^{8}$
}

1, 2, 3, 4, 5, 6, 7, 8 Department of Ophthalmology, Mysore Medical College and Research Institute, Mysore, Karnataka, India.

\section{ABSTRACT}

\section{BACKGROUND}

Blindness is a major health problem worldwide and India has been an epicenter in the number of blindness cases. The causes of blindness, natural history differs between western countries and India. When it comes to optic neuritis the pattern in developing countries is different than developed countries. Multiple sclerosis is one of the major causes of disability disease in US and one of the most common early manifestations is optic neuritis. Early identification and early management have shown promises in reducing ocular morbidity as well as neurological morbidity and recurrences. But the trend of optic neuritis in India is very different and not many studies have been conducted to know about this disease and its causes in this geographical region. We wanted to evaluate the clinical profile and visual outcome of optic neuritis in India.

\section{METHODS}

It was a prospective study done for a duration of $10.8+/-8.4$ months in which all patients clinically diagnosed with optic neuritis were studied. Thirty patients were included in the study. They were followed up and visual parameters were assessed and thus clinical profiling and visual outcomes were done.

\section{RESULTS}

Mean age was $39.3667 \pm 14.03563$ years. Female preponderance was seen $(63.33 \%$ of cases). Retrobulbar neuritis (56.7 \% of eyes) was more common than papillitis ( $43.33 \%$ of eyes) but papillitis was a more common presentation in males (73.7 \%). Bilateral presentation was seen in $23.33 \%$ cases. All patients complained of DOV but pain on ocular movements were complained by $36.66 \%$ patients. Baseline median $\operatorname{logMAR}$ visual acuity $(\mathrm{VA})$ was $1.17 \pm 0.8$, which improved to $1.6 \pm 0.6$, within one week and $0.79+/-0.6$ within one month improving to $0.55+/-0.6$ in three months. Approximately $64.68 \%$ of eyes retained VA of or $6 / 18$ or more. Colour vision recovery was noted in $39.86 \%$. Demyelinating lesions in the brain were present in 2 patients, one of which was already diagnosed as MS. One case on follow up was eventually diagnosed as multiple sclerosis.

\section{CONCLUSIONS}

In Indian scenario the profile of optic neuritis is different. Here incidence of papillitis is more or equal to that of retrobulbar optic neuritis, visual recovery is poor, causes being more of infectious or idiopathic and less recurrence rate.

\section{KEY WORDS}

Optic Neuritis, Clinical Profile, Visual Outcome, Developing Countries Ontt
Corresponding Author: Dr. Gajaraj Tulsidas Naik, Karwar Institute of Medical Sciences, Karwar, Karnataka, India. E-mail: gajrajnaik@gmail.com

DOI: $10.14260 /$ jemds/2021/568

How to Cite This Article:

Naik GT, Krishnamurthy H, Kumar SMP, et al. Clinical profile and visual outcome of optic neuritis patients in Mysore medical college and research institute, India. J Evolution Med Dent Sci 2021;10(33): 2784-2788, DOI:

$10.14260 /$ jemds/2021/568

Submission 17-05-2021,

Peer Review 11-07-2021,

Acceptance 18-07-2021,

Published 16-08-2021.

Copyright (C) 2021 Gajaraj Tulsidas Naik et al. This is an open access article distributed under Creative Commons Attribution License [Attribution 4.0 International (CC $B Y 4.0)]$ 


\section{BACKGROUND}

Inflammation of the optic nerve is called optic neuritis. Causes being infectious, autoimmune and demyelinating diseases especially multiple sclerosis. $20 \%$ of multiple sclerosis patients present with optic neuritis. ${ }^{1}$ During the course of the disease $60-70 \%$ will develop into multiple sclerosis. ${ }^{2}$ Optic neuritis presents with sudden loss of vision usually unilateral with pain on ocular movements. Usually a self-limiting disease but can have significant vision loss. Patient may complain on symptoms getting aggravated after heat exposure (Cutoff's symptoms) or even experiencing glowing sensations with non-photic stimulus (Phosphine's). Patient may have lowered dark adaptation time, impairment of color vision and impaired depth perception known as Pulfrich phenomenon. Usually symptoms will gradually resolve by 4 weeks. This type of optic neuritis is more common in young or middle aged usually women associated with demyelinating diseases having good visual recovery. This is called typical optic neuritis. Whereas in other cases presentation will be different with old aged or children, male patients with usually infectious/ parainfectious causes with bad prognosis. This type is called atypical optic neuritis.

When coming to ophthalmoscopic findings it presents as three variants - retrobulbar neuritis, papillitis and neuroretinitis. Retrobulbar optic neuritis is the inflammation of optic nerve behind the eyeball. Fundus picture will be normal except in advanced cases where temporal pallor may be seen. Demyelinating disease is the most common cause. Papillitis features as disc edema with hyperaemia and peripapillary haze, common cause being inflammatory or infectious. Neuroretinitis consists of optic nerve involvement with surrounding retinal involvement presenting as macular star formation, because being infectious in origin. In many cases it may be difficult to find the cause naming them as idiopathic in origin. There can be remissions, relapses or also can go for chronic optic neuritis. ${ }^{3}$

Optic neuritis affects visual quality that includes visual acuity, contrast and visual field defects leading to visual impairment and also a future predictor of demyelinating diseases. ${ }^{4}$ So ophthalmologist has a very significant role to aid in the prevention of full blown MS. Fortunately it has a good prognosis in most of the cases. Depending upon the severity of condition one can recover completely or partially depending upon co-morbidity. ${ }^{5}$ Optic neuritis usually affects middle aged and younger people but there have been reported incidences of optic neuritis in old and young till the age of four. ${ }^{4}$ The incidence rate in US is $5.1 / 10000$. Incidence is more commonly seen in middle aged women. Optic neuritis treatment trial (ONTT) was the most important study to highlight about optic neuritis. It was a huge trial conducted in US which followed optic neuritis, evaluated its course and also treatment response with various steroids. ${ }^{6}$ In developing countries like India the clinical profile of optic neuritis is somewhat different ${ }^{7}$ and not many studies have been done on it. A few studies clarify that the scenario in Indian subcontinent is different as infectious diseases play an important role in the cause of optic neuritis and prognosis is not so good. ${ }^{8}$

Hence this study was done to focus on possible causative factor, risk and visual outcome of optic neuritis in Indian set up.

\section{METHODS}

It was a prospective study done for a duration of $10.8+/-8.4$ months in which all the patients clinically diagnosed with optic neuritis were studied and those with anterior ischaemic optic neuropathy and traumatic optic neuropathy were excluded.

\section{Sample Size}

Sample size was detected based on a pilot study for the following parameters; level of significance, absolute error $\mathrm{d}=$ $10 \%$. Sample median proportion related parametric and nonparametric tests were done. On an average 2.5 patients were diagnosed with optic neuritis every month, hence 30 cases were taken for the study.

Paper was presented in the ethical committee of Mysore medical college and research institute, Mysore and clearance was obtained. Patients with optic neuritis were admitted after taking valid consent and detailed history was taken, with documention of onset of visual loss, duration of visual loss, pain on ocular movements and any other associated symptoms.

Clinical examination included visual acuity testing with Snellen chart, pupil reflex and presence of relative afferent pupillary defect (RAPD), fundus examination with 78D lens, colour vision by pseudoisochromatic test plates, visual field by automated perimetry, contrast sensitivity by Pelli-Robson chart. Routine blood investigations were done including CBC, ESR, total counts and other tests to rule out infective causes. If affordable, Magnetic resonance imaging of the brain and orbit with contrast were done. All patients were treated as per treatment guidelines and their follow ups were done from June 2016 to June 2017. At all follow up visits, examination included Snellens visual acuity testing, evaluation of pupils, slit lamp biomicroscopy with 78D, colour vision, contrast sensitivity and visual field. Data was recorded in a specially designed proforma which was transferred to master sheet and statistically analysed.

\author{
Statistical Methods \\ Descriptive statistics used \\ Cramers V \\ Chi square test \\ Student T test \\ Paired t test \\ Cramers V and SPSS software version 16.0 were used
}

\section{RESULTS}

Out of total 30 patients 1 was under age group < 20 yrs [3.3 $\%$ ], seven [23.3\%] patients belonged to age group of $21-30$ yrs, seven [23.3\%] were in the age group of $31-40$ yrs, four [13.3\%] were under fifty yrs and majority of the patients came under 41 - 50 yrs i.e eleven [36.7 \%]. Less number of patients in extremes of age group i.e $<20$ yrs and $>50$ yrs. Both retrobulbar neuritis and papillitis were common in the age group of $41-50 \mathrm{yrs}$. The mean age of presentation was $39.3667 \pm 14.03563[16-75]$. Out of 30 patients retrobulbar 
neuritis was diagnosed in 17 [56.7 \%] whereas papilitis was diagnosed in 13 [43.3\%]. Out of thirty patients 19 [63.33\%] were females and 11 [36.66 \%] were males i.e the female preponderance was seen in a ratio of 1.72:1. Among males, papilitis was more commonly seen [73.7 \%] but RBN was noted more commonly in females [73.7 \%].

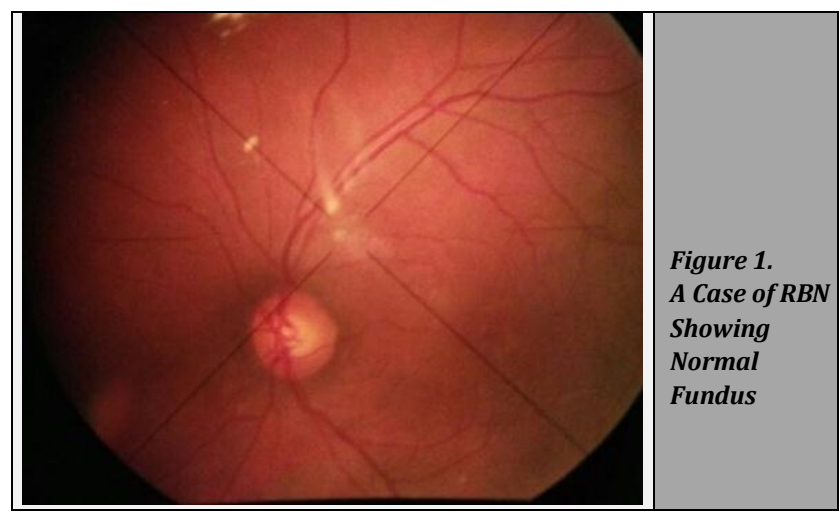

Patient presented with sudden onset of unilateral vision loss with RAPD and dyschromatopsia and loss of contrast. The loss of colour vision was disproportionate to loss of VA. Vision recovered from $6 / 36$ to $6 / 6$ after ONTT regimen. MRI was normal in this patient suggestive of isolated clinical syndrome of MS in form of RBN. [Courtesy picture taken by hand held mobile phone attached to kowa fundus camera, Dept of Ophthalmology, KR Hospital, Mysore].
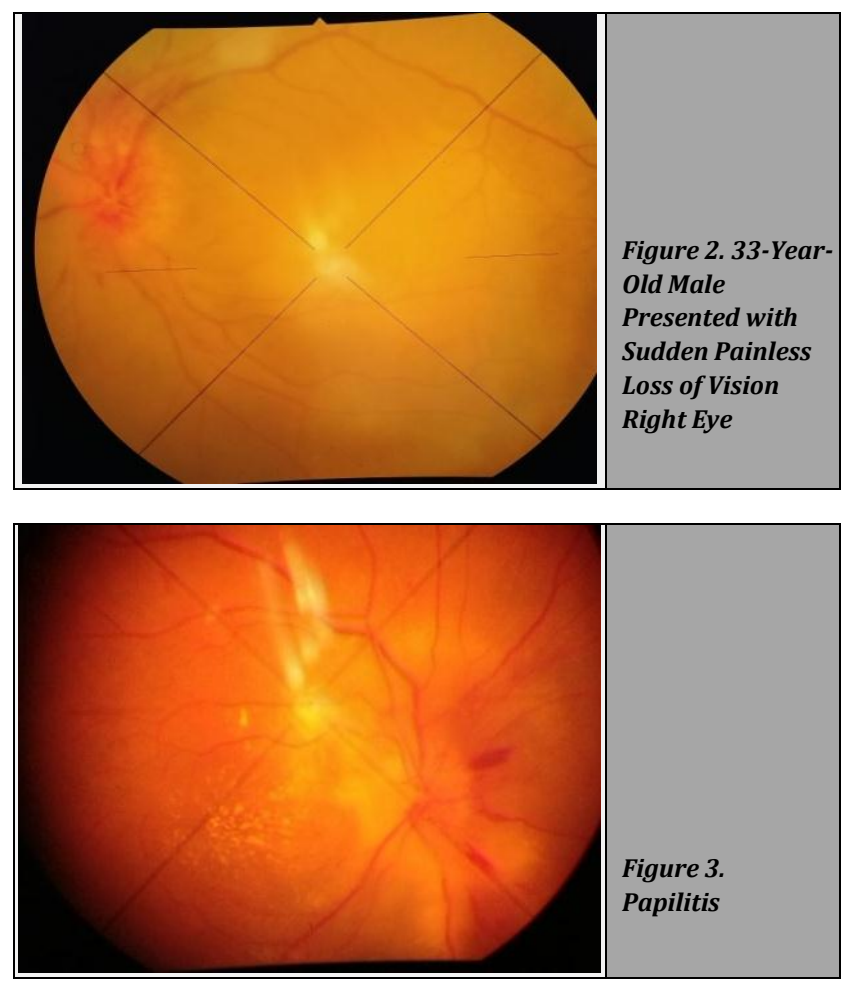

Examination demonstrated a best-corrected visual acuity of 6/60. Fundus revealed optic nerve head edema, peripapillary haze, retinal hemorrhages, and vitreous opacities. On blood investigations Toxo IgM antibodies were positive. The patient was treated with pyrimethamine, sulfadiazine, folinic acid along with ONTT regimen. Three months later BCVA was 6/18. [Courtesy picture taken by hand held mobile phone attached to kowa fundus camera, Dept of Ophthalmology, KR Hospital, Mysore].

Fig no 3 showing papilitis with macular exudates in the form of star shape - neuroretinitis. Patient had PL+ at presentation with ONTT regimen combined with systemic antibiotics, vision recovered to 6/60.[Courtesy picture taken by hand held mobile phone attached to kowa fundus camera, Dept of Ophthalmology, KR Hospital, Mysore].

Bilateral presentation was seen in 7 cases [23.33\%], 6 of whom had papilitis and 1 had retrobulbar neuritis. Left eye was more commonly involved than right eye i.e 1.55:1. Out of thirty patients 2 patients had similar history in past, 1 was a diagnosed case of MS and other was retrobulbar neuritis. Recurrance rate was $6.66 \%$. DOV was seen in all patients with optic neuritis, out of 17 RBN cases 11 [36.66\%] patients complained of pain with eye movements and 6 [20\%] patients complained of nonspecific pain in and around the eye. 1 patient had uhthoff's phenomenon. All patients with optic neuritis had pupil abnormality at presentation. $76.66 \%$ had RAPD and $23.33 \%$ had sluggishly reacting pupil. After treatment i.e at one week RAPD was detected in only $20 \%$ of cases, and at the end of one month RAPD was noted in $10 \%$ of cases and at the end of 3 months it was $6.66 \%$ of cases. In case of bilateral disease after treatment pupil was sluggishly reacting in $16.66 \%$ cases and later after 3 months it was reduced to $13.33 \%$. At end of 3 months $80 \%$ had normal pupillary reflex. At presentation initially there were no cases with normal pupil reaction but after treatment the number of cases with normal pupil spiked at 1 month. Also the number of cases with RAPD steeped downwards than cases with sluggish reacting pupils in about 1 week duration.

\begin{tabular}{|c|c|c|c|c|}
\hline VA & At Presentation & $\begin{array}{l}\text { After ONTT } \\
\text { [one week] }\end{array}$ & $\begin{array}{c}\text { One } \\
\text { Month }\end{array}$ & $\begin{array}{l}\text { Three } \\
\text { Months }\end{array}$ \\
\hline PL+ & 4.35 & - & & \\
\hline CF T0 6/60 & 40.57 & 3.23 & 3.23 & 3.23 \\
\hline $6 / 60-6 / 36$ & 48.56 & 19.95 & 11.62 & 4.72 \\
\hline $6 / 36-6 / 18$ & 6.52 & 30.44 & 28.65 & 27.91 \\
\hline $6 / 18-6 / 6$ & - & 46.38 & 60.52 & 64.16 \\
\hline P VALUE & - & $0.030^{* * *}$ & 0.006 & 0.002 \\
\hline \multicolumn{5}{|c|}{ Table 1. Visual Acuity Comparison before and after Treatment } \\
\hline $\begin{array}{l}\text { based on paired } \\
\text { *significant at } p \\
\text { ** significant at } p\end{array}$ & $\begin{array}{l}\text { test } \\
\text { alue }<0.05 \\
\text { alue }<0.01\end{array}$ & & & \\
\hline
\end{tabular}

All patients at presentation had vision worse than $6 / 18$ with majority of the patients having vision between $6 / 60$ and $6 / 36$ and $4.35 \%$ had PL+. After treatment majority had vision between $6 / 18-6 / 6$ [46.38\%] and was statistically significant. Also after 1 month and 3 months majority had vision between 6/18 and 6/6 [60.52 \% and $64.56 \%$ respectively]. Only $3.23 \%$ had VA less than $6 / 60$ after 3 months. In case of RBN, $90.1 \%$ of patients had DOV for less than one month i.e they improved to $6 / 6$ after ONTT regimen within 1 month whereas the scenario was reversed in case of papilitis wherein $84.2 \%$ complained of persistence of vision loss even after 4 months i.e vision didn't improve to $6 / 6$ at 1 month duration. Papillitis patients took longer time to recover. Most of them had defective colour vision at presentation [77.97\%]. About $13.44 \%$ of patients colour vision was not able to record due to poor vision. After 3 months, colour vision improved. Residual colour vision defect persisted in $56.91 \%$ of patients. There was no correlation statistically but colour vision improved grossly with treatment and time. 


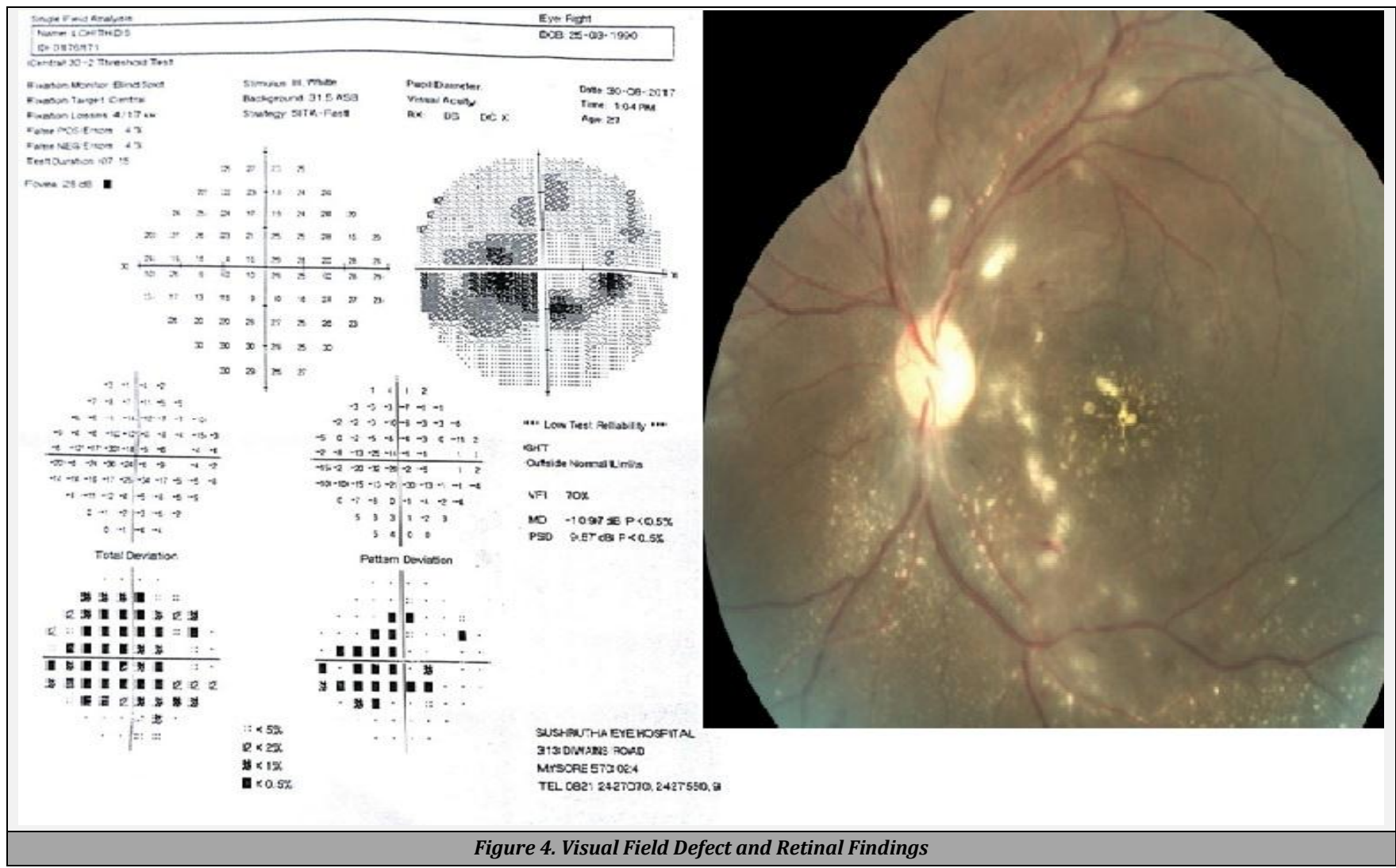

Most of them had reduced contrast sensitivity at presentation [83.33\%]. About $13.44 \%$ of patients contrast sensitivity was not able to record due to poor vision. Some patients showed improvement in contrast sensitivity whereas majority didn't after ONTT regimen. At the end of 3 months reduced contrast sensitivity was noted in $86.91 \%$. There was no statistically correlation.

A total of 28 eyes were unable to undergo visual field examination due to poor vision and lack of learning curve. Among patients who had visual field done, majority had central and centrocecal scotoma seen in $45.31 \%$, followed by arcuate scotoma in $34.3 \%$ and inferior altitudinal defect in $6.64 \%$.

Patient presented with sudden bilateral diminution since 7 days with history of fever about 1 month back. On examination patient vision was PL+ with fundus showing atypical optic neuritis. Patient was started with ONTT with systemic antibiotic cover. Vision improved to $6 / 60$ and later after 3 months to $6 / 6$. But patient still complained of field defect and loss of contrast. Humphrey field analyser (HFA) was done showing centrocaecal scotoma which was was the major finding in our study.

Fundus picture of the same patient mentioned above [I N Fig 4] showing disc pallor, resolving exudates, sheathing. This picture was taken after 3 months of ONTT regimen. Patient had 6/6 vision but loss of contrast and field defect as depicted above.

Most common fundus findings were disc edema and peripapillary haze suggestive of papilitis. Apart from these there were temporal pallor in two patients, haemorrhages in two patients, macular exudates in four patients, sheathing in three patients and retinochoroiditis in one patient. Results of the blood investigations were abnormal in 5 cases of papilitis. 3 had lymphocytosis, 1 raised ESR and another tested positive for Toxo IgM antibodies.
Chest $x$ ray and Mantoux were normal in all cases. Due to financial reasons MRI was done in only 11 cases. Of these 11 cases, three cases showed signal intensity in optic nerve. Two patients had demyelinating lesions in the brain, one of which was already diagnosed as MS. One case was eventually diagnosed as MS. This patient also had internuclear ophthalmoplegia (INO) with convergence involved. She also tested positive for oligoclonal bands in CSF. The recurrence rate in our study was $6.66 \%$.

Other ocular manifestations were not seen apart from INO. In systemic manifestations one patient had transverse myelitis. Other nonspecific ocular findings in our study were cataract, glaucoma and corneal opacity.

\section{DISCUSSION}

The ONTT study was the most important study which helped analyse about optic neuritis. Later on there were innumerable studies on optic neuritis. ${ }^{9}$ Studies from US and other western countries showed higher incidence of MS when compared to studies from Asia and Africa. ${ }^{10,11,12,13,14}$ An Indian study conducted by Rohit Saxena et al. before the commencement of the ONTT had indicated that the profiling of optic neuritis in India was different from the western countries. ${ }^{8,15}$ Apart from the above studies no other study is available that clarifies the status of $\mathrm{ON}$ in India.

Similar correspondence was seen regarding the age of presentation and female preponderance in the present study with that of western. ${ }^{10,11}$ Bilaterality was seen in $23.33 \%$ of the patients in the present study compared to $15 \%$ - $35 \%$ reported in other studies conducted by Woung LC et al. and Lim SA et al.12,13 whereas an African study conducted by 
Pokroy R et al..$^{13}$ had reported it to be very high i.e more than $80 \%$.

There was slightly increased frequency of retrobulbar neuritis which was different compared to other Indian studies. But our study showed that the incidence of RBN was similar to ONTT study. This indicates that RBN is also commonly seen in Asian population.

There was also absence of pain in our study of about $45 \%$ which was consistent with other Asian studies. ${ }^{15}$ According to ONTT study the recovery rate of optic neuritis was vey good with more than $90 \%$ improvement of upto $6 / 12$ or better. ${ }^{16}$ In our study only $64.16 \%$ of the patients could recover VA to this level. In both unilateral and bilateral cases amount of visual recovery was the same. (58\% versus $57.6 \%$ gaining VA of $6 / 12$ or more) which is comparable to an Indian study done earlier by Jain IS et al. ${ }^{17}$ similar results indicating poor visual prognosis were seen in other Asian studies. ${ }^{13,14,8}$ Some studies from Africa showed extremely poor prognosis. ${ }^{14}$

Recurrence was seen in 2 cases i.e $6.66 \%$ and was more common with RBN. When compared to ONTT the recurrence rate was extremely less. ${ }^{15}$ This noncordence may be due to small sample size and brief study duration in the present study. Two patients had neuro imaging status linked to MS i.e eventually diagnosed and two cases had already been diagnosed prior to this study. MRI was not done in all the cases of optic neuritis in our study, but many studies from this region has showed decreased incidence of MS. $10,11,12,13,14,18$

\section{CONCLUSIONS}

This study showed that presentation of optic neuritis varies from that of western studies. It showed that the visual outcome of optic neuritis was poor, with equal incidence of both papillitis and RBN, demyelinating diseases being less frequent causes and recovery rate being less.

\section{Limitations}

The limitations of our study include not obtaining MRI in all cases. We have known that optic neuritis in this region was different from that reported in the Western population but in our case papillitis was equal in incidence as retrobulbar neuritis, association with MS was low, and visual outcome seemed good.

Data sharing statement provided by the authors is available with the full text of this article at jemds.com.

Financial or other competing interests: None.

Disclosure forms provided by the authors are available with the full text of this article at jemds.com.

\section{REFERENCES}

[1] Balcer LJ. Clinical practice. Optic neuritis. New England Journal of Medicine 2006;354(12):1273-80.

[2] Sorensen TL, Frederiksen JL, Bronnum-Hansen H, et al. Optic neuritis as onset manifestation of multiple sclerosis: a nationwide, long-term survey. Neurology 1999;53(3):473-8.

[3] Voss E, Raab P, Trebst C, et al. Clinical approach to optic neuritis: pitfalls, red flags and differential diagnosis. Ther Adv Neurol Disord 2011;4(2):123-34.

[4] "NEI Clinical Studies." Optic Neuritis Treatment Trial (ONTT). National Eye Institute, n.d. Web. 23 Aug, 2013.

[5] Menon V, Saxena R, Misra R, et al. Management of optic neuritis. Indian Journal of Ophthalmology 2011;59(2):117-22.

[6] Optic Neuritis Study Group. Visual function 15 years after optic neuritis a final follow- up report from the optic neuritis treatment trial. Ophthalmology 2008;115(6):1079-82.e5.

[7] Un Nisa A, Khan A, Shah PA. Clinical profile of optic neuritis in kashmiri population. J Med Sci and Clin Res 2018;6(10):1337-40.

[8] Saxena R, Phuljhele S, Menon V, et al. Clinical profile and short-term outcomes of optic neuritis patients in India. Indian J Ophthalmol 2014;62(3):265-7.

[9] Rodriguez M, Siva A, Cross SA, et al. Optic neuritis: a population-based study in Olmsted County, Minnesota. Neurology 1995;45(2):244-50.

[10] Wakakura M, Minel-Higa R, Oono S, et al. Baseline features of idiopathic optic neuritis as determined by a multicenter treatment trial in Japan. Optic Neuritis Treatment Trial Multicenter Cooperative Research Group (ONMRG). Jpn J Ophthalmol 1999;43(2):127-32.

[11] Wang JC, Tow S, Aung T, et al. The presentation, aetiology, management and outcome of optic neuritis in an Asian population. Clin Experiment Ophthalmol 2001;29(5):312-5.

[12] Woung LC, Lin CH, Tsai CY, et al. Optic neuritis among national health insurance enrollees in Taiwan, 20002004. Neuroepidemilogy 2007;29(3-4):250-4.

[13] Lim SA, Goh KY, Tow S, et al. Optic neuritis in Singapore. Singapore Med J 2008;49(9):667-71.

[14] Pokroy R, Modi G, Saffer D. Optic neuritis in urban black African community. Eye (Lond) 2001;15(Pt 1):469-73.

[15] Optic Neuritis Study Group. The clinical profile of acute optic neuritis: experience of the Optic Neuritis Treatment Trial. Arch Ophthalmol 1991;109(12):1673-8.

[16] Jain IS, Munjal VP, Dhir SP, et al. Profile of optic neuritis in Chandigarh and surrounding areas. Indian J Ophthalmol 1980;28(4):195-200.

[17] Beck RW, Cleary PA, Backlund JC. The course of visual recovery after optic neuritis. Experience of Optic Neuritis Treatment Trial. Ophthalmology 1994;101(11):1771-8.

[18] Filippi M, Rocca MA, Ciccarelli O, et al. MRI criteria for the diagnosis of multiple sclerosis: MAGNIMS consensus guidelines. Lancet Neurol 2016;15(3):292-303. 